\title{
Desenvolvimento de bezerras de corte após a desmama sob níveis de concentrado
}

\author{
After weaning beef heifers development under supplementation levels
}

\author{
Luciana Pötter ${ }^{\mathrm{I}}$ Marta Gomes da Rocha" ${ }^{\mathrm{II}}$ Stefani Macari ${ }^{\mathrm{II}}$ Juliano Roman $^{\mathrm{II}}$ Dalton Roso $^{\mathrm{II}}$ \\ Carine Lisete Glienke ${ }^{\mathrm{II}}$ Aline Tatiane Nunes da Rosa ${ }^{\mathrm{II}}$
}

\section{RESUMO}

Foi avaliado o desenvolvimento de bezerras de corte recebendo diferentes niveis diários de suplemento concentrado: 0,0;0,3;0,6 e 0,9\% do peso corporal em pastagem de aveia preta (Avena strigosa Schreb.) e azevém (Lolium multiflorum Lam.). O delineamento experimental foi o inteiramente casualizado, com quatro tratamentos e duas repetições de área. As bezerras tiveram condições similares de disponibilidade de pasto (massa de forragem e oferta de lâminas verdes) em todos os tratamentos. Aumentos na quantidade fornecida de suplemento interferiram positivamente no ganho médio diário, na carga animal, no ganho de peso por área e na eficiência de transformação da forragem. Bezerras suplementadas apresentaram maior peso corporal e maior escore de condição corporal aos 13 meses de idade em relação às não suplementadas. Em aveia preta e azevém, fornecer até $0,9 \%$ do peso corporal dos animais em suplementação concentrada é uma alternativa para serem obtidas novilhas mais pesadas e com melhor escore de condição corporal.

Palavras-chave: Avena strigosa, crescimento animal, fêmeas bovinas de corte, Lolium multiflorum, pastejo contínuo.

\section{ABSTRACT}

It was evaluated the performance of beef heifers receiving different levels of supplement: 0; 0.3; 0.6 and $0.9 \%$ of body weight day ${ }^{-1}$, in black oats (Avena strigosa Schreb.) plus Italian ryegrass (Lolium multiflorum Lam.) pasture. The experimental design was completely randomized with four treatments and two area replicates. Beef heifers from different treatments had access to the same forage allowance (herbage mass and supply of green leaves). Increases on supplement quantity positively interfered on average daily gain, stocking rate, weight gain per area and forage transformation efficiency. Supplemented heifers had greater weight and body condition at 13 months of age than the non supplemented ones. In black oats plus Italian ryegrass pasture, providing up to $0.9 \%$ of body weight of the animal concentrate supplementation is an alternative for obtaining heavier heifers and in better body condition score.

Key words: animal growth, Avena strigosa, beef heifers, continuous grazing, Lolium multiflorum.

\section{INTRODUÇÃO}

Na bovinocultura de corte, o desempenho produtivo do rebanho de cria é afetado de maneira marcante pela variação de peso e estado corporal das fêmeas. Entre os fatores responsáveis por essas variações, encontram-se as flutuações quantitativas e qualitativas das pastagens e os fatores genéticos.

No Rio Grande do Sul, a desmama dos bezerros/as de corte é realizada no outono, e a recria dos animais é influenciada negativamente pela menor quantidade e qualidade das pastagens nativas durante o período de inverno. Isso resulta em redução no desempenho desses animais e idade elevada por ocasião do início da reprodução. Dentro desse contexto, a utilização de pastagens cultivadas de estação fria, tais como a aveia preta (Avena strigosa Schreb) e o

'Programa Pós-graduação em Zootecnia, Centro de Educação Superior Norte-RS (CESNORS), Universidade Federal de Santa Maria(UFSM), Rua Floriano Peixoto, 730/05, 97010-310, Santa Maria, RS, Brasil. E-mail: potter.luciana@ gmail.com. Autor para correspondência.

IIPrograma Pós-graduação em Zootecnia, UFSM, Santa Maria, RS, Brasil. 
azevém (Lolium multiflorum Lam.), aliadas à suplementação energética, são uma alternativa que pode resultar em alto desempenho individual e por área no período pós desmama das bezerras (PÖTTER et al., 2010).

O principal objetivo da suplementação para animais em pastejo é aumentar o consumo total de matéria seca e energia em relação ao consumo atingido exclusivamente com pasto (BARGO et al., 2003), determinando acréscimo no aporte de nutrientes aos animais, denominado de "efeito aditivo" e que ocasiona aumento do ganho individual. O aumento na taxa de lotação pode decorrer do "efeito de substituição" do consumo de pasto pelo consumo de suplemento (HODGSON, 1990). As relações entre a quantidade de suplemento e os efeitos de substituição e adição, em pastagens de estação fria, ainda necessitam ser mais bem esclarecidas, para que possam ser transferidas para os sistemas de produção.

Estratégias apropriadas de suplementação de novilhas necessitam de uma melhor compreensão sobre o efeito do fornecimento de diferentes quantidades de suplemento concentrado em relação ao peso corporal dos animais em pastejo. $\mathrm{O}$ fornecimento de diferentes quantidades de subprodutos (farelo de arroz + polpa cítrica) ou grão de sorgo, em aveia e azevém, foi avaliado por FRIZZO et al. (2003) e PILAU et al. (2004), respectivamente. Esses autores usaram níveis de suplemento que variaram de 0,5 a $1,5 \%$ do peso corporal, e as relações entre ganho individual e aumento na quantidade de suplemento não foram lineares. Já a taxa de lotação, em ambos os experimentos, aumentou à medida que aumentou a quantidade de suplemento.

Este trabalho foi conduzido com objetivo de avaliar o desempenho de bezerras de corte, em recria, recebendo diferentes níveis de suplemento concentrado em pastagem de aveia preta + azevém, no primeiro inverno pós-desmama.

\section{MATERIAL E MÉTODOS}

O experimento foi desenvolvido no Departamento de Zootecnia da Universidade Federal de Santa Maria, Rio Grande do Sul (RS), na região da Depressão Central do Rio Grande do Sul. Foi avaliado o desempenho de bezerras de corte em pastejo recebendo níveis de suplemento concentrado correspondentes a 0,$0 ; 0,3 ; 0,6$ e $0,9 \%$ do peso corporal em pastagem de aveia preta mais azevém. O suplemento continha $14 \%$ de proteína bruta e $18,8 \%$ de fibra em detergente neutro, composto de farelo de trigo, farelo de arroz e milho, fornecido diariamente às 14 horas.
O método de pastejo foi contínuo, sendo utilizados três animais testes e um número variável de reguladores por repetição para manter valores de massa de forragem entre $1.200 \mathrm{e} 1.500 \mathrm{~kg} \mathrm{ha}^{-1}$ de matéria seca. $\mathrm{O}$ delineamento experimental foi o inteiramente casualizado em parcelas subdivididas no tempo, com quatro tratamentos, duas repetições de área e quatro períodos de avaliação.

A área experimental totalizou 6,3ha, com oito subdivisões de 0,7 ha mais uma área contígua de 0,9 ha. A pastagem foi estabelecida pelo método de preparo mínimo, em 19 de maio de 2004 , e foram utilizados $250 \mathrm{~kg}$ $\mathrm{ha}^{-1}$ da fórmula 05-20-20 (NPK), 60 $\mathrm{kg} \mathrm{ha}^{-1}$ de sementes de aveia preta e $50 \mathrm{~kg} \mathrm{ha}^{-1}$ de sementes de azevém. Em cobertura, foram aplicados $77 \mathrm{~kg} \mathrm{ha}^{-1}$ de nitrogênio, parcelados em três aplicações. O período de estabelecimento foi de 49 dias, mais 19 dias de adaptação dos animais e 95 dias de avaliação (27/07 a 29/10/2004).

A massa de forragem foi determinada utilizando-se a técnica de estimativa visual por dupla amostragem. Para a avaliação da taxa de acúmulo diário de forragem, foram utilizadas três gaiolas de exclusão ao pastejo por piquete. As perdas de forragem foram determinadas conforme HILLESHEIM (1998).

Os animais experimentais foram bezerras da raça Charolês e suas cruzas com Nelore, com idade de oito meses e peso médio no início do experimento de $124,9 \pm 9 \mathrm{~kg}$. O ganho médio diário das bezerras foi obtido pela diferença dos pesos final e inicial em cada período experimental, dividido pelo número de dias deste. Por ocasião das pesagens, foi avaliado o escore de condição corporal dos animais com valores de 1 (muito magro) a 5 (muito gordo) (LOWMAN et al., 1973).

A carga animal, por período, foi obtida pela soma do peso médio dos animais testes mais o peso médio dos animais reguladores multiplicado pelo número de dias que estes permaneceram na pastagem, dividido pelo número de dias do período de pastejo, sendo expressa em $\mathrm{kg} \mathrm{ha}^{-1}$ de peso corporal. O ganho de peso por hectare foi obtido pelo produto da taxa de lotação, ganho médio diário dos animais teste e número de dias do período.

A oferta de forragem ( $\mathrm{kg}$ de matéria seca $100 \mathrm{~kg}$ de peso corporal ${ }^{-1}$ ) foi calculada por meio da divisão do valor da massa de forragem pelo número de dias, mais a taxa diária de acúmulo de matéria seca. Esse valor foi dividido pela carga animal e, posteriormente, multiplicado por 100. A oferta de lâminas foliares verdes foi calculada pelo produto entre a oferta de forragem e a porcentagem total de lâminas foliares verdes. A oferta total de matéria seca foi calculada pelo somatório da oferta de forragem mais a 
oferta de suplemento ( $\mathrm{kg}$ de matéria seca do suplemento $100 \mathrm{~kg}$ de peso corporal ${ }^{-1}$ ).

Os teores de proteína bruta e fibra em detergente neutro (ASSOCIATION OF OFFICIAL ANALYTICAL CHEMISTS-AOAC, 1990) foram quantificados no pasto aparentemente consumido pelos animais, coletado pela técnica da simulação de pastejo e também no suplemento.

O consumo estimado de matéria seca foi calculado pelo método agronômico, em \% do peso corporal, e a massa de forragem existente no final do período experimental $\mathrm{e}$ as perdas de forragem ocorridas durante o período de pastejo foram subtraídas da produção total de matéria seca e o valor obtido foi dividido pela carga animal média.

A eficiência de transformação de $\mathrm{kg}$ de forragem em peso corporal foi obtida pela razão entre a forragem desaparecida e o ganho de peso por área. A eficiência de transformação de $\mathrm{kg}$ de suplemento em peso corporal foi obtida por meio da divisão entre a quantidade de suplemento fornecido aos animais suplementados e o ganho de peso adicional por área em relação ao uso exclusivo da pastagem.

As variáveis estudadas foram submetidas à análise de variância e regressão polinomial até terceira ordem, com nível de 5\% de probabilidade. Quando não foi detectada diferença entre níveis de suplemento, foi realizado teste de contraste entre animais suplementados e não suplementados. As análises foram realizadas utilizando-se o programa estatístico SAS, versão 8.2 (SAS, 2001).

\section{RESULTADOS E DISCUSSÃO}

A adequação da taxa de lotação, durante o período experimental, foi eficiente para manter valores de massa de forragem semelhantes $(\mathrm{P}>0,05)$ nos piquetes utilizados em pastejo por animais recebendo os diferentes níveis de suplemento. Também os valores médios de oferta de forragem + suplemento e oferta de lâminas foliares verdes da pastagem de aveia preta mais azevém foram similares $(\mathrm{P}>0,05$; Tabela 1$)$. $\mathrm{O}$ valor médio de massa de forragem foi de $1.469 \mathrm{~kg} \mathrm{ha}^{-1} \mathrm{de}$ matéria seca, dentro da faixa de valores recomendados para essas forrageiras para bom desempenho dos animais sem afetar a produção de forragem (PILAU et al., 2004).

O valor médio para a taxa de acúmulo de forragem durante o período de pastejo foi de $44,5 \mathrm{~kg} \mathrm{ha}^{-1}$ $\mathrm{dia}^{-1}$, e a oferta de forragem + suplemento foi de $12,8 \mathrm{~kg}$ de MS 100kg de peso corporal ${ }^{-1}$. Com uso exclusivo de forrageiras, esse valor assegura o exercício da seletividade pelos animais em pastejo (HODGSON, 1990).

Não houve interação nível de suplemento $x$ dias de pastejo $(\mathrm{P}>0,05)$ para as variáveis ganho médio diário, carga animal, ganho de peso por área e eficiência de transformação do pasto, tendo essas variáveis se ajustado ao modelo de regressão linear em função dos níveis de suplemento (Figura 1).

Houve efeito linear positivo no ganho médio diário conforme o incremento do nível de suplemento (Figura 1a), e o nível 0,9\% de suplemento representou incremento de $35 \%$ em relação a animais exclusivamente em pastagem. $\mathrm{O}$ consumo de suplemento proporcionou taxa de adição no consumo total de matéria seca de $100 \%$ para os níveis 0,3 e $0,6 \%$ e de $6,6 \%$ para o nível $0,9 \%$, provocando uma maior ingestão de energia que se mostrou efetiva em aumentar a taxa de ganho de peso.

No nível mais alto de suplementação, a relação volumoso: concentrado na dieta foi de 75:25. Quando as bezerras receberam $0,9 \%$ do peso corporal de suplemento, não foram verificados os efeitos negativos sobre o seu desempenho que poderiam advir de uma alta proporção de carboidratos prontamente digestíveis na dieta. Com altos níveis de concentrado, a estrutura física da dieta não favorece a secreção salivar para manter o pH ruminal entre 6 e 7 , e não há estímulo adequado para a motilidade ruminal e

Tabela 1 - Valores médios de massa de forragem, oferta de forragem + suplemento e oferta de lâminas foliares verdes em pastagem de aveia mais azevém com bezerras de corte recebendo diferentes níveis de suplemento ${ }^{1}$.

\begin{tabular}{|c|c|c|c|c|c|}
\hline \multirow{2}{*}{ Variáveis } & \multicolumn{5}{|c|}{ - } \\
\hline & 0,0 & 0,3 & 0,6 & 0,9 & Média \\
\hline Massa forragem, $\mathrm{kg} \mathrm{ha}^{-1} \mathrm{MS}$ & 1451,8 & 1392,6 & 1494,3 & $1537,2^{\text {ns }}$ & $1469,0 \pm 61,7$ \\
\hline $\begin{array}{l}\text { Oferta de forragem }+ \text { suplemento, } \mathrm{kg} \\
\text { MS } 100 \mathrm{~kg} \text { peso corporal }\end{array}$ & 13,9 & 13,2 & 13,5 & $10,9^{\mathrm{ns}}$ & $12,8 \pm 1,3$ \\
\hline $\begin{array}{l}\text { Oferta de lâminas foliares verdes, } \\
\mathrm{kg}^{\mathrm{MS}} 100 \mathrm{~kg} \text { peso corporal }\end{array}$ & 3,6 & 4,6 & 4,1 & $4,7^{\text {ns }}$ & $4,3 \pm 0,5$ \\
\hline
\end{tabular}

${ }^{1}$ ns= médias não diferem entre $\mathrm{si}(\mathrm{P}>0,05)$ 


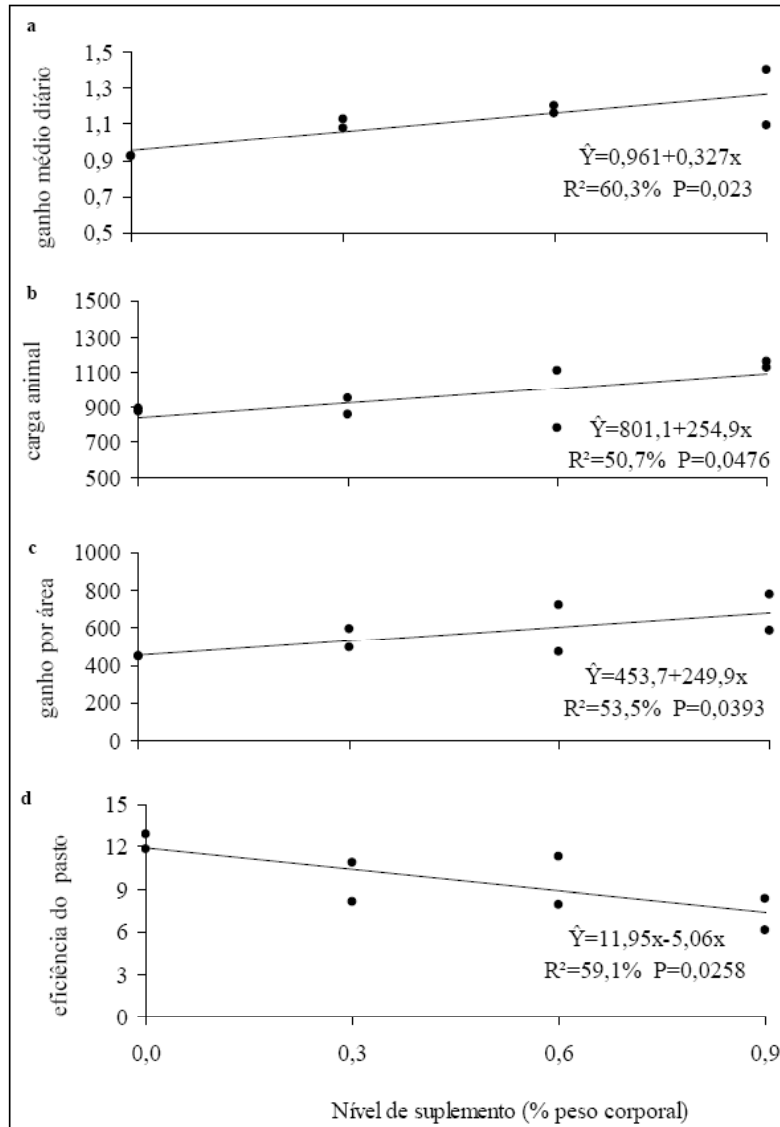

Figura 1 - Valores médios (pontos) e estimados (linha) de ganho médio diário $(\mathrm{kg})$, carga animal $(\mathrm{kg}$ ha de peso corporal $\left.^{-1}\right)$, ganho de peso por área $(\mathrm{kg})$ e de eficiência de transformação do pasto em produto animal ( $\mathrm{kg}$ de peso corporal) para bezerras de corte em pastagem de aveia preta mais azevém em função dos níveis de suplemento.

ruminação. Em consequência, o desempenho dos animais pode diminuir, pois a eficiência de síntese de proteína microbiana é reduzida quando o $\mathrm{pH}$ é menor que 6 (RUSSEL, 2002). Também há redução na concentração de amônia, em razão do efeito negativo do $\mathrm{pH}$ sobre a taxa de desaminação bacteriana (LANA et al., 2000).

Os animais experimentais, sendo levados em consideração sua idade e seu grupo genético, apresentavam baixo peso corporal $(124,9 \mathrm{~kg})$ por ocasião do início do período de pastejo. Essa foi a razão, provavelmente, do valor do ganho médio diário observado $\left(1,114 \mathrm{~kg} \mathrm{dia}^{-1}\right)$ ter sido superior aos ganhos verificados em bezerras de corte do mesmo rebanho em outros experimentos com as mesmas espécies forrageiras (FRIZZO et al., 2003; PILAU et al., 2004). O baixo peso pode ter determinado, durante o período experimental, um ganho compensatório nos animais, o qual envolve a redução na exigência de energia para mantença e o aumento na eficiência do uso da energia metabolizável acima da mantença (FOX et al., 1988).

O fornecimento de $0,9 \%$ do peso corporal de suplemento proporcionou valores $30 \%$ superiores de carga em relação ao uso exclusivo da pastagem. A carga animal aumentou de forma linear crescente (Figura 1b), o que correspondeu a 1,4 bezerras a mais, com peso corporal médio de $182,8 \mathrm{~kg}$ para cada aumento de $1 \%$ no nível de suplemento. Os consumos de matéria seca do pasto foram de 3,56 e 2,72\% do peso corporal para animais exclusivamente em pastagem e recebendo $0,9 \%$ de suplemento, respectivamente. Isso caracteriza um coeficiente de substituição do consumo de pasto pelo consumo de suplemento de 0,93 , o qual explica o aumento na taxa de lotação.

$\mathrm{O}$ incremento no ganho médio diário e na carga animal se refletiu no ganho de peso por área, o qual também se elevou linearmente com os níveis de suplemento (Figura 1c). A elevação do ganho de peso por área, à medida que aumentou o nível de suplemento, também foi observada por FRIZZO et al. (2003) e PILAU et al. (2004), para valores de suplemento de até $1,5 \%$ do peso corporal.

A suplementação dos animais permitiu melhor eficiência de transformação do pasto em produto animal, sendo a relação linear decrescente entre a quantidade de forragem necessária para produzir um kg de peso corporal e os níveis de suplemento (Figura 1d). Em aveia preta e azevém, foram relatadas eficiências de 13,5 e 11,1kg de MS $\mathrm{kg}^{-1}$ de ganho de peso, valores próximos aos obtidos para animais não suplementados (RESTLE et al., 2000).

A eficiência de transformação do suplemento fornecido foi de 2,5; 3,5 e 4,0kg de suplemento por $\mathrm{kg}$ de ganho de peso adicional por hectare nos níveis de 0,$3 ; 0,6$ e $0,9 \%$ do peso corporal, respectivamente. Essas relações foram mais eficientes que as encontradas por FRIZZO et al. (2003) em pastagem de aveia preta mais azevém quando o suplemento foi constituído por farelo de arroz integral mais polpa cítrica (1:1). Esse resultado pode estar relacionado ao ganho compensatório realizado pelos animais, que promove maior eficiência na utilização dos nutrientes. A composição do suplemento, com fontes ricas em amido (30\%) e fibra solúvel $(70 \%)$, além de balanceados os demais nutrientes, também pode ter interferido. Existe menor alteração dos padrões ruminais, favorecendo o desempenho individual, 
quando é utilizada uma fonte de energia rica em fibra solúvel (ELIZALDE et al., 1998).

O consumo estimado de matéria seca variou com o decorrer do período de pastejo $(\mathrm{P}=0,0001)$, diminuindo no final da utilização da pastagem, quando foi verificado o maior efeito aditivo do suplemento. Animais que receberam suplemento, no final do ciclo das forrageiras, realizaram ganho individual superior em 50,2\% ao ganho dos animais exclusivamente em pastagem $(\mathrm{P}<0,05)$. Também FRIZZO et al. (2003) verificaram maiores incrementos no ganho dos animais suplementados no período final de utilização da pastagem, quando a suplementação com 0,7 e $1,4 \%$ do peso corporal de farelo de arroz integral + polpa cítrica proporcionou ganho médio diário 72,2 e $107 \%$ superior em relação aos animais não suplementados.

Não houve interação entre níveis de suplemento $x$ dias $(\mathrm{P}>0,05)$ para a concentração de proteína bruta da forragem. A suplementação não alterou $(\mathrm{P}>0,05)$ o teor de proteína da forragem consumida pelos animais em pastejo. O percentual de proteína bruta mostrou melhor ajuste ao modelo linear decrescente $\left(\hat{\mathrm{Y}}=28,1-0,2 \mathrm{x} ; \mathrm{R}^{2}=0,88 ; \mathrm{P}=0,0001\right)$ ao longo do período de utilização da pastagem. De acordo com a equação de regressão, a partir de 19 de setembro de 2004 e prolongando-se até o final do ciclo das forrageiras, o teor de proteína bruta do pasto ficou abaixo do teor de $12,1 \%$, necessário para ganhos de $0,900 \mathrm{~kg} \mathrm{dia}^{-1} \mathrm{em}$ bezerras de corte com $180 \mathrm{~kg}$ e 10 meses de idade (National Research Council - NRC, 1996). Nesse período de 40 dias finais do ciclo da forrageira, então, é de extrema importância o nível proteico do suplemento, que foi de $14 \%$, para otimizar o desempenho individual.

Houve interação níveis de suplemento $x$ dias de utilização da pastagem $(\mathrm{P}<0,05)$ para os valores de fibra em detergente neutro do pasto. A suplementação influenciou $(\mathrm{P}<0,05)$ o teor de fibra em detergente neutro da forragem aparentemente consumida entre o $27^{\circ} \mathrm{eo}$ $83^{\circ}$ dia de pastejo (22/08-17/10). No período entre 22/ 08/2004 a 19/09/2004 (27 $-54^{\circ}$ dia), houve ajuste ao modelo linear de regressão $\left(\hat{\mathrm{Y}}=38,1-5,8 \mathrm{x} ; \mathrm{R}^{2}=0,60\right.$; $\mathrm{P}=0,02)$, o que indica, provavelmente, à medida que se elevou o nível de suplemento, que houve um maior consumo de lâminas foliares, as quais possuem menor teor de fibra em detergente neutro. No período entre 19/09/2004 e 17/10/2004 (55 ${ }^{\circ}-83^{\circ}$ dia), observou-se efeito quadrático do nível de suplemento sobre o teor de fibra em detergente neutro da forragem aparentemente colhida $\left(\hat{Y}=46,9+15,3 x-25,4 x^{2} ; R^{2}=0,88 ; P=0,008\right)$, em que o maior teor de fibra em detergente neutro foi verificado na forragem consumida por animais suplementados com $0,3 \%$ do peso corporal. Nos demais períodos, inicial e final de pastejo, a suplementação não influenciou o teor de fibra em detergente neutro da forragem aparentemente consumida pelos animais.

A alta disponibilidade de lâminas foliares (relação folha:colmo de 4:1), nos primeiros 26 dias de pastejo, provavelmente foi o principal fator que possibilitou a colheita de forragem com teores de fibra em detergente neutro semelhantes (32\% da MS) para os níveis de suplemento avaliados. A estrutura da pastagem, no período de pleno florescimento do azevém, com relação folha:colmo reduzida $(0,1: 1)$ e valor médio de $53,6 \%$ da matéria seca de fibra em detergente neutro, não permitiu aos animais suplementados mudarem a seleção do alimento frente aos não suplementados. A alta concentração de fibra faz com que a repleção ruminal limite a ingestão pelos animais em pastejo.

Não houve interação nível de suplemento x dias de pastejo para o peso corporal inicial e final, ganho de peso por área, ganho de escore de condição corporal e escore de condição corporal inicial e final. O uso do suplemento permitiu que as novilhas apresentassem um maior ganho de peso a cada dia de pastejo $\left(\hat{\mathrm{Y}}=124,2+1,2 \mathrm{x} ; \mathrm{R}^{2}=0,91 ; \mathrm{P}<0,0001\right)$ em relação às não suplementadas $\left(\hat{\mathrm{Y}}=122,0+0,962 \mathrm{x} ; \mathrm{R}^{2}=0,95 ; \mathrm{P}<0,0001\right)$, fato explicado pela maior ingestão de energia pelos animais suplementados, já discutido anteriormente.

O peso corporal e escore de condição corporal ao final do primeiro inverno são de fundamental importância para estabelecer a idade ao primeiro acasalamento de novilhas. Independentemente do nível de suplemento utilizado, as novilhas não conseguiram atingir o peso e o escore de condição corporal mínimos necessários para acasalamento aos 14/15 meses, equivalente a $65 \%$ do peso adulto e 3,0 a 3,5 pontos de escore de condição corporal. Ao final do período experimental, em 29 de outubro de 2004, as novilhas apresentaram $72,1 \%$ do peso corporal a ser atingido no início do seu acasalamento, de $325 \mathrm{~kg}$, considerando peso adulto projetado de $500 \mathrm{~kg}$ de peso corporal para o grupo racial utilizado. Embora tenha existido alto desempenho dos animais, o baixo peso ao início do pastejo, correspondente a apenas $25 \%$ do peso adulto projetado, foi determinante para a impossibilidade de seu acasalamento aos 14/15 meses de idade.

$\mathrm{O}$ escore de condição corporal médio dos animais ficou em 2,85 pontos, inferior ao escore de 3,9 verificado por FRIZZO et al. (2003) em novilhas oriundas do mesmo rebanho, após suplementação em pastagens de aveia preta e azevém. Novilhas suplementadas apresentaram um maior ganho no escore de condição corporal $\left(\hat{\mathrm{Y}}=2,54+0,0034 \mathrm{x} ; \mathrm{R}^{2}=0,78 ; \mathrm{P}<0,0001\right) \mathrm{em}$ relação às não suplementadas $(\hat{Y}=2,54+0,0028 x$; 
$\left.\mathrm{R}^{2}=0,85 ; \mathrm{P}<0,0001\right)$ nos 96 dias de período experimental. Houve tendêndia $(\mathrm{P}=0,068)$ de ajuste à equação de regressão linear do escore de condição corporal final com o nível de suplemento dos animais indicando um relacionamento positivo entre nível de suplemento e escore de condição corporal no final do período alimentar. $\mathrm{O}$ pequeno ganho de escore de condição corporal é explicado pelo baixo peso corporal ao início do experimento, sendo o ganho de peso atribuído ao desenvolvimento muscular (ROCHA et al., 2007).

\section{CONCLUSÃO}

A suplementação concentrada para bezerras de corte em pastejo em aveia preta e azevém, em quantidade de até $0,9 \%$ do peso corporal, influencia positivamente o seu desempenho e desenvolvimento pós-desmama, sendo uma alternativa para obter animais mais pesados e com melhor condição corporal, viabilizando a antecipação do primeiro acasalamento.

\section{REFERÊNCIAS}

ASSOCIATION OF OFFICIAL ANALITICAL CHEMISTS AOAC. Official methods of analysis. 15.ed. Arlington, 1990. 1298p.

BARGO, F. et al. Invited review: production and digestion of supplemented dairy cows on pasture. Journal of Dairy Science, v.86, n.1, p.1-42, 2003. Disponível em: <http:// www.journalofdairyscience.org/article/S0022-0302(03)735814/fulltext>. Acesso em: 21 fev. 2008. doi: 10.3168/jds.S00220302(03)73581-4.

ELIZALDE, J.C. et al. Performance and digestion by steers grazing tall fescue and supplement with energy and protein. Journal of Animal Science, v.76, n.4, p.1691-1701, 1998. Disponível em: <http://jas.fass.org/cgi/reprint/76/6/169>. Acesso em: 22 jan. 2008.

FOX, D.G. et al. Adjusting nutrient requirements of beef cattle for animal and environmental variations. Journal of Animal Science, v.66, n.6, p.1475-1495, 1988. Disponível em: <http:/ /jas.fass.org/cgi/reprint/66/6/1475>. Acesso em: 10 fev. 2008.

FRIZZO, A. et al. Suplementação energética na recria de bezerras de corte mantidas em pastagem de inverno. Revista Brasileira de Zootecnia, v.32, n.3, p.643-652, 2003. Disponível em: <http:// www.scielo.br/scielo.php?pid=S151635982003000300016\&script $=$ sci _arttext\&tlng=es>. Acesso em: 10 fev. 2008. doi: 10.1590/S151635982003000300016 .
HILLESHEIM, A. Manejo do gênero Pennisetum sob pastejo. In: SIMPÓSIO SOBRE MANEJO DA PASTAGEM, 9., 1998, Piracicaba, SP. Anais... Piracicaba: FEALQ, 1998. p.77-108.

HODGSON, J. Grazing management: science into practice. Essex: Longman, 1990. 203p.

LANA, R.P. et al. Efeito da acidez no controle da produção de amônia e crescimento microbiano. Revista Brasileira de Zootecnia, v.29, n.6, p.1876-1882, 2000. Disponível em: <http://www.scielo.br/scielo.php? pid=S 1516 $35982000000600037 \&$ script $=$ sci_arttext\&tlng =es $>$. Acesso em: 10 fev. 2008. doi: 10.1590/S1516-35982000000600037.

LOWMAN, B.G. et al. Condition scoring beef cattle. Edinburgh: East of Scotland College of Agriculture, 1973. 8p. (Bulletin 6).

NATIONAL RESEARCH COUNCIL - NRC. Nutrient requirements of beef cattle. 7.ed. Washington, D.C.: National Academy, 1996. 248p.

PILAU, A. et al. Recria de novilhas de corte com diferentes níveis de suplementação energética em pastagem de aveia-preta e azevém. Revista Brasileira de Zootecnia, v.33, n.6, p.2104-2113, 2004. Disponível em: <http://www.scielo.br/ scielo.php? script=sci_arttext\&pid=S 1516 35982004000800023>. Acesso em: 10 fev. 2008. doi: 10.1590/ S1516-35982004000800023.

PÖTTER, L. et al. Suplementação com concentrado para novilhas de corte mantidas em pastagens cultivadas de estação fria. Revista Brasileira de Zootecnia, v. 39, n.5, p. 992-1001, 2010. Disponível em: <http://www.scielo.br/scielo.php?script=sci_arttext\&pid=S151635982010000500008\&lng=en\&nrm=iso>. Acesso em: 09 ago. 2010. doi: 10.1590/S1516-35982010000500008.

RESTLE, J. et al. Produtividade animal e retorno econômico em pastagem de aveia preta mais azevém adubada com fontes de nitrogênio em cobertura. Revista Brasileira de Zootecnia, v.29, n.2, p.357-364, 2000. Disponível em: <http://www.scielo.br/ scielo.php? script $=$ sci_arttext \& pid = S 1516 35982000000200006>. Acesso em: 29 jan. 2008. doi: 10.1590/ S1516-35982000000200006.

ROCHA M.G. et al. Sistemas intensivos de produção de gado de corte - ênfase na recria de fêmeas. In: GOTTSCHALL, C. (Ed.) CICLO DE PALESTRAS EM PRODUÇÃO E MANEJO DE BOVINOS, 12., 2007, Canoas, RS. Anais... Canoas: ULBRA, 2007. p.100-120.

RUSSELL, J.B. Rumen microbiology and its role in ruminant nutrition. Ithaca: Cornell University, 2002. 119p.

SAS. Statistical analysis system user's guide: statistics. Version 8.2. Cary: Statistical Analysis System Institute, 2001. $1686 \mathrm{p}$. 